\title{
2-Phenylethylamine and Methamphetamine Enhance the Spinal Monosynaptic Reflex by Releasing Noradrenaline from the Terminals of Descending Fibers
}

\author{
Hideki Ono, Hiroyuki Ito and Hideomi Fukuda ${ }^{1}$ \\ Department of Toxicology and Pharmacology, Faculty of Pharmaceutical Sciences, \\ The University of Tokyo, Hongo 7-3-1, Bunkyo-ku, Tokyo 113, Japan \\ 'Department of Pharmacology, College of Pharmacy, Nihon University, \\ 7-7-1 Narashinodai, Funabashi, Chiba 274, Japan
}

Received July 28, 1990 Accepted December 27, 1990

\begin{abstract}
Experiments were performed on spinalized rats transected at $\mathrm{C} 1$. Intravenous administration of 2-phenylethylamine- $\mathrm{HCl}$ (PEA-HCl) $(0.3$ and $1 \mathrm{mg} / \mathrm{kg}$, i.v.) and methamphetamine-HCl (MAP-HCl) $(0.1$ and $0.3 \mathrm{mg} / \mathrm{kg}$, i.v. $)$ increased the amplitude of the monosynaptic reflex (MSR). The increase of the MSR caused by PEA and MAP was antagonized by prazosin- $\mathrm{HCl}$ and abolished by the pretreatment with reserpine (i.p.) and 6-hydroxydopamine (intracisternally, 14 days previously). A dopamine $D_{1}$ antagonist, SK\&F $83566-\mathrm{HBr}(0.01 \mathrm{mg} / \mathrm{kg}$, i.v. $)$, and a $\mathrm{D}_{2}$ antagonist, YM-09151-2 (0.3 mg/kg, i.v.), did not antagonize the increasing effects produced by PEA and MAP. An inhibitor of type-B monoamine oxidase, $(-)$ deprenyl- $\mathrm{HCl}(1$ $\mathrm{mg} / \mathrm{kg}$, i.v.), prolonged the effect of PEA but not that of MAP, suggesting that PEA alone, and not its metabolites, enhanced the MSR. These results suggest that PEA and MAP increase the amplitude of the MSR by releasing noradrenaline from the terminals of descending noradrenergic fibers, and that PEA, an endogenous trace amine, has a mechanism of action similar to that of MAP.
\end{abstract}

2-Phenylethylamine (PEA) is one of the endogenous trace amines present in mammals (1, 2). PEA is similar to amphetamine in its chemical structure and some pharmacological actions. Like amphetamine, PEA produces stereotyped behavior, increases locomotor activity and decreases feeding behavior (3-5). Thus it could be considered that PEA is an endogenous amphetamine-like substance. However, the mechanism of the synaptic action of PEA has not yet been clarified.

PEA is abundant in the caudate nucleus, putamen, globus pallidus and cerebellum in man (2) and relatively abundant in the rat spinal cord (6). The spinal monosynaptic reflex (MSR) of spinalized animals can be used as a clear and simple tool for elucidating the mechanisms of drug action. Noradrenergic and serotonergic descending neurons innervate the spinal ventral horn (7), and $\alpha_{1}$-agonistic action and serotonergic actions enhance (8) and decrease the MSR $(9-11)$, respectively. Thus, the MSR is a useful tool for evaluating amphetamines which affect the monoaminergic terminals. We have shown previously that low doses of PEA and MAP increase the MSR and that high doses decrease it $(12-14)$. In the present study, the mechanisms of the 
MSR-enhancing action of PEA and MAP were compared in detail using spinalized rats.

\section{MATERIALS AND METHODS}

\section{Recording of MSR}

Male Wistar rats, weighing $300-400 \mathrm{~g}$, were anesthetized with urethane $(1 \mathrm{~g} / \mathrm{kg}$, i.p. $)$ and $\alpha$-chloralose $(25 \mathrm{mg} / \mathrm{kg}$, i.p.) and then artificially ventilated. The bilateral vagus nerves were severed at the cervical region, and the spinal cord was transected at the $\mathrm{C} 1$ level. Laminectomy was performed in the lumbosacral region. The ventral and dorsal roots below L4 were cut bilaterally, and the dorsal and ventral roots of segments $\mathrm{L} 4$ and L5 were isolated. A skin pouch was formed at the site of the dissection so that the exposed tissues could be covered with liquid paraffin kept at $36 \pm$ $0.5^{\circ} \mathrm{C}$. Rectal temperature was maintained at $36 \pm 0.5^{\circ} \mathrm{C}$ by a heating pad. The dorsal and ventral roots of segment L5 were placed on bipolar silver-silver chloride wire electrodes for stimulation $(0.2 \mathrm{~Hz}, 0.05 \mathrm{msec}$, supramaximal) and recording, respectively. The reflex potentials were amplified (Nihon Kohden AVB-10), displayed on an oscilloscope (Nihon Kohden VC-10) and averaged 8 times by an averaging computer (Nihon Kohden DAT$1100)$, the analog output of which was recorded by a recorder (Toa FBR-252A). The amplitude of the MSR was then measured.

Blood pressure in the femoral artery was monitored with a transducer (Bentley Trantec model 800) and recorded on a polygraph (Nihon Kohden RM-25).

\section{Drug treatment}

Rats were pretreated with several drugs. Prazosin- $\mathrm{HCl} \quad(1 \mathrm{mg} / \mathrm{kg}), \quad \mathrm{SK} \& \mathrm{~F} \quad 83566-\mathrm{HBr}$ $(0.01 \mathrm{mg} / \mathrm{kg})$, YM-09151-2 (0.3 mg/kg), (-) deprenyl-HCl $(1 \mathrm{mg} / \mathrm{kg}$, i.v.) and phentolamine mesylate $(2 \mathrm{mg} / \mathrm{kg})$ were administered intravenously $10 \mathrm{~min}$ before injection of PEA or MAP. Reserpine $(5 \mathrm{mg} / \mathrm{kg}$, i.p.) was administered $24 \mathrm{hr}$ before PEA or MAP injection.

Pretreatment with 6-hydroxydopamine was performed 14 days before recording of the MSR. Rats were anesthetized with ether and given an intracisternal injection of 6-hydroxydopamine $(200 \mu \mathrm{g}$ free base in $10 \mu \mathrm{l}$ saline with $0.1 \%$ ascorbic acid), whereas controls were administered $10 \mu \mathrm{l}$ ascorbic acid. After the skin had been sutured all animals received penicillin-G potassium (100,000 I.U.) and kanamycin sulfate $(10 \mathrm{mg})$ intramuscularly.

\section{Drugs}

Drugs used were 2-phenylethylamine- $\mathrm{HCl}$ (Tokyo Kasei), $\mathrm{S}(+)$ methamphetamine- $\mathrm{HCl}$ (Dainjppon), prazosin-HCl (Pfizer), phentolamine mesylate (Regitin Injection, Ciba Geigy), (-)deprenyl-HCl (Research Biochemical Inc.), reserpine (Apoplon Injection, Daiichi), 6-hydroxydopamine-HCl (Sigma), SK\&F 83566- $\mathrm{HBr}$ (Smith Kline \& French Labs.) and YM-09151-2 (Yamanouchi). Prazosin- $\mathrm{HCl}$ was dissolved in $\mathrm{HCl}$ solution and prepared at $\mathrm{pH} 3$, and 6-hydroxydopamine- $\mathrm{HCl}$ was dissolved in saline with $0.1 \%$ ascorbic acid. Other drugs were dissolved in physiological saline.

\section{Statistics}

Student's $t$-test (two-tailed) was employed to compare control values with treated values. When the population variances were unequal, Welch's procedure (15) was employed. Control and drug-treated data were obtained alternately in each graph of figures. One animal received only one injection of PEA or MAP, because PEA and MAP caused tachyphylaxis.

\section{RESULTS}

Enhancements of MSR by PEA and MAP and antagonism by the $\alpha_{1}$-antagonist prazosin

$\mathrm{PEA}-\mathrm{HCl}(0.3$ and $1 \mathrm{mg} / \mathrm{kg}$, i.v. $)$ and MAP$\mathrm{HCl}(0.1$ and $0.3 \mathrm{mg} / \mathrm{kg}$, i.v. $)$ increased the amplitude of the MSR (Fig. 1, A, B). The time courses of the effects of PEA and MAP were short and long, respectively; the effects of PEA disappeared within $10 \mathrm{~min}$, whereas those of MAP continued for more than 30 min. In the presence of the $\alpha_{\mathrm{I}}$-blocker 

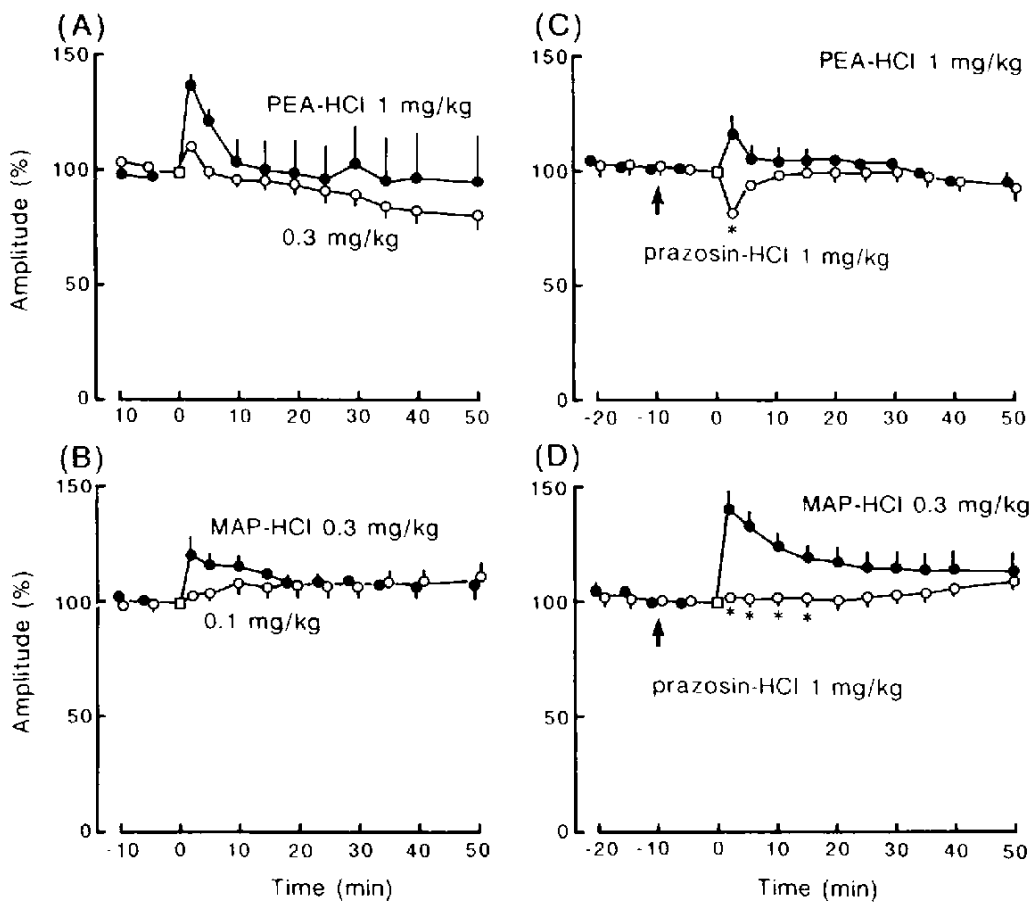

Fig. 1. Effect of PE.A- $\mathrm{HCl}$ and $\mathrm{MAP}-\mathrm{HCl}$ on the MSR ( $\mathrm{A}$ and $\mathrm{B}$ ) and antagonism by prazosin- $\mathrm{HCl}(\mathrm{C}$ and D). Abscissae: time aftcr the injection of PEA or MAP. Ordinates: reflex amplitude (mean \pm S.E.M. for 4 experiments) calculated as a percentage of the value just prior to injection of PEA or MAP. (A) : PEA$\mathrm{HCl} 1 \mathrm{mg} / \mathrm{kg}$, i.v.; ( PEA-HCl $0.3 \mathrm{mg} / \mathrm{kg}$, i.v. (B) O: MAP-HCl $0.3 \mathrm{mg} / \mathrm{kg}$, i.v.; O: MAP-HCl 0.1 $\mathrm{mg} / \mathrm{kg}$, i.v. (C) : PEA-HCl $1 \mathrm{mg} / \mathrm{kg}$, i.v.; $\bigcirc$ : prazosin- $\mathrm{HCl} 1 \mathrm{mg} / \mathrm{kg}$, i.v. $+\mathrm{PEA}-\mathrm{HCl} 1 \mathrm{mg} / \mathrm{kg}, \mathrm{i} . \mathrm{v}$. (D) : MAP-HCl $0.3 \mathrm{mg} / \mathrm{kg}$, i.v.; O: prazosin-HCl $1 \mathrm{mg} / \mathrm{kg}$, i.v. + MAP-HCl $0.3 \mathrm{mg} / \mathrm{kg}$, i.v. Prazosin was administered at the arrow. Where S.E.M. bars are not shown, they lie within the dimension of the symbols. ${ }^{*} \mathrm{P}<0.05$ ( $t$-test), as compared with the effect of PEA or MAP alone.

prazosin- $\mathrm{HCl}$ ( $1 \mathrm{mg} / \mathrm{kg}$, i.v.), the increasing effects of PEA were reversed to a decrease (Fig. 1C). The enhancement of MSR caused by MAP was completely abolished by prazosin (Fig. 1D). Prazosin alone did not affect the MSR in the spinalized rats that were used in the present study.

Effects of the dopamine $D_{I}$ antagonist $S K \& F$ 83566- $\mathrm{HBr}$ and the $\mathrm{D}_{2}$ antagonist YM-09151-2

Pretreatment with the $\mathrm{D}_{1}$ antagonist $\mathrm{SK} \& \mathrm{~F}$ $83566-\mathrm{HBr}(0.01 \mathrm{mg} / \mathrm{kg}$, i.v. $)$ or the $\mathrm{D}_{2}$ antagonist YM-09151-2 (0.3 mg/kg, i.v.) did not alter the effects of PEA and MAP on the MSR (Fig. 2). These doses of SK\&F 83566$\mathrm{HBr}$ and YM-09151-2 antagonized the increasing effect of the $\mathrm{D}_{1}$ agonist SK\&F 38393-HBr $(1 \mathrm{mg} / \mathrm{kg}, \mathrm{i} . \mathrm{v}$.$) and the decreasing effect of$ the $\mathrm{D}_{2}$ agonist apomorphine- $\mathrm{HCl}(3 \mathrm{mg} / \mathrm{kg}$, i.v.) on the MSR, respectively (not shown). SK\&F 83566-HBr and YM-09151-2 tended to increase and decrease the MSR, respectively.

\section{Influences of reserpine and 6-hydroxydopamine treatments}

Reserpine $(5 \mathrm{mg} / \mathrm{kg}$, i.p.), which depletes monoamines in the monoaminergic terminals, administered $24 \mathrm{hr}$ before PEA and MAP, abolished the increase of the MSR produced by the latter agents (Fig. 3, A, B). PEA decreased the MSR in reserpinized rats.

Pretreatment (14 days, previously) with intracisternal 6-hydroxydopamine, which destroys monoaminergic terminals, reduced the enhancing effects of PEA and MAP on the MSR without changing the pressor effects of 

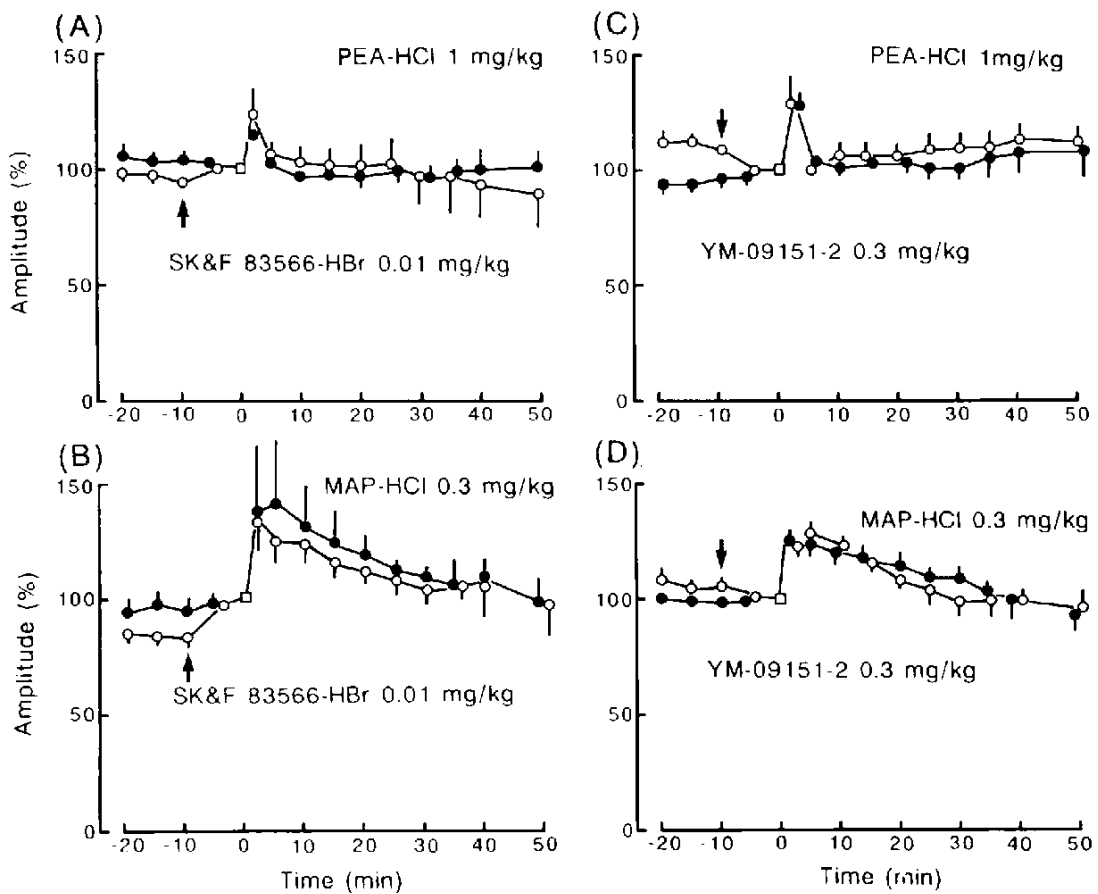

Fig. 2. Influence of SK\&F 83566- $\mathrm{HBr}(\mathrm{A}$ and $\mathrm{B})$ and $\mathrm{YM}-09151-2$ (C and D) on the stimulatory effects of PEA and MAP on the MSR. (A) O: PEA-HCl $1 \mathrm{mg} / \mathrm{kg}$, i.v.; O: SK\&F $83566-\mathrm{HBr} 0.01 \mathrm{mg} / \mathrm{kg}$, i.v. + PEA-HCl $1 \mathrm{mg} / \mathrm{kg}$, i.v. (B) O: MAP-HCl $0.3 \mathrm{mg} / \mathrm{kg}$, i.v.; O: SK\&F $83566-\mathrm{HBr} 0.01 \mathrm{mg} / \mathrm{kg}$, i.v. + MAP$\mathrm{HCl} 0.3 \mathrm{mg} / \mathrm{kg}$, i.v. (C) : PEA-HCl $1 \mathrm{mg} / \mathrm{kg}$. i.v.; $\mathrm{YM}-09151-20.3 \mathrm{mg} / \mathrm{kg}$, i.v. $+\mathrm{PEA}-\mathrm{HCl} 1 \mathrm{mg} / \mathrm{kg}$, i.v. (D) : MAP-HCl $0.3 \mathrm{mg} / \mathrm{kg}$, i.v.; : YM-09151-2 $0.3 \mathrm{mg} / \mathrm{kg}$, i.v. + MAP-HCl $0.3 \mathrm{mg} / \mathrm{kg}$, i.v. SK\&F 83566- $\mathrm{HBr}$ and $\mathrm{YM}-09151-2$ were administered at the arrow. $\mathrm{n}=4$.

PEA and MAP (Fig. 3, C, D). The treatment with reserpine or 6-hydroxydopamine did not change the amplitude and latency of MSR.

\section{Influences of a monoamine oxidase inhibitor} and blood pressure

An inhibitor of type-B monoamine oxidase (MAO), (-)deprenyl-HCl ( $1 \mathrm{mg} / \mathrm{kg}$, i.v.), did not reduce, but increased and prolonged the enhancing effects of PEA $(0.3 \mathrm{mg} / \mathrm{kg}, \mathrm{i} . \mathrm{v}$.$) on$ the MSR (Fig. 4A). The time coursc of the effect of MAP $(0.3 \mathrm{mg} / \mathrm{kg}$, i.v.) was not affected by (-)deprenyl (Fig. 4B). These results suggested that the short action of PEA is due to its rapid metabolism.

The possibility was also tested that changes in the MSR caused by PEA and MAP are due to peripheral changes in blood pressure. Phentolamine mesylate $(2 \mathrm{mg} / \mathrm{kg}, \mathrm{i} . v$. $)$ antagonized the pressor cffects of PEA and MAP without changing their enhancing effects on the MSR (Fig. 4, C, D).

\section{DISCUSSION}

Effects of drugs on the polysynaptic reflex (PSR) were not described in this study, since excitatory effects of PEA and MAP on the PSR were variable and the influences of drugtreatment on the PSR were not significant.

It has been considered that changes in the MSR caused by PEA and MAP may be due to peripheral changes in blood pressure. Phentolamine, which seems to have difficulty in penetrating the blood-brain barrier, antagonized the pressor effects but not the enhancing effects of PEA and MAP on the MSR (Fig. 4). In addition, pretreatment with intracisternal 6-hydroxydopamine, which destroys monoaminergic terminals in the CNS (16), antago- 

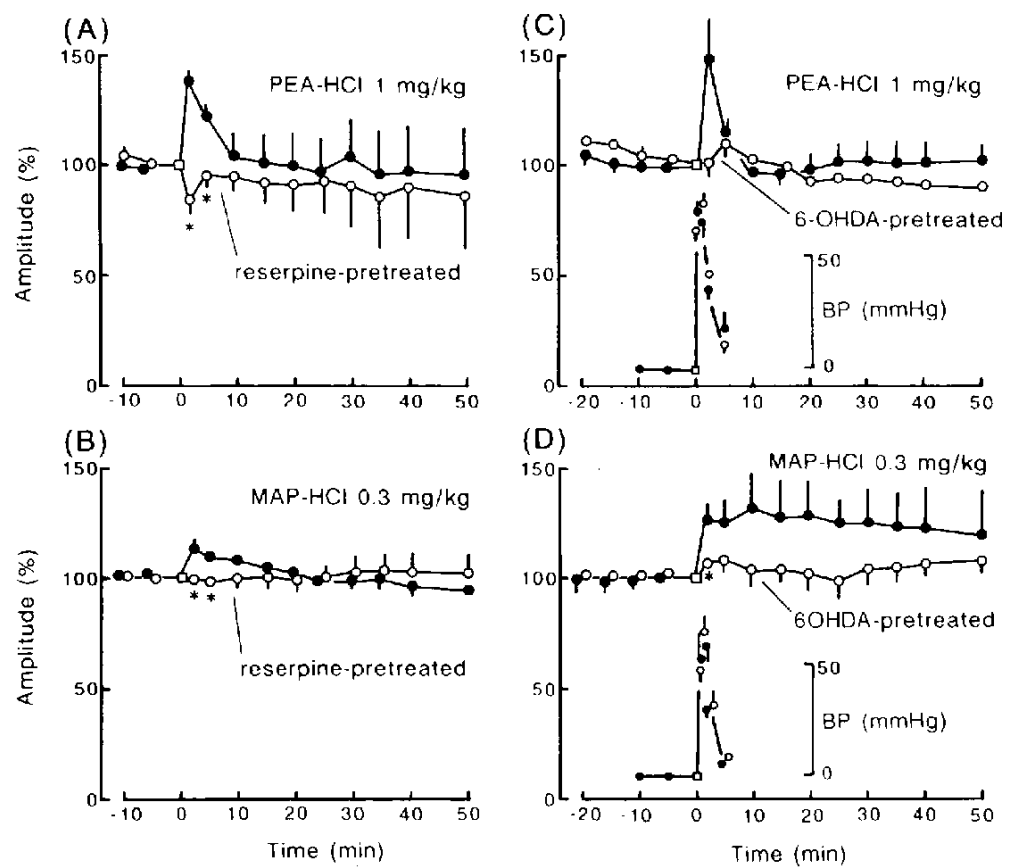

Fig. 3. Influence of depletion of monoamines by reserpine (A and B) and 6-hydroxydopamine (C and D) on the stimulatory effects of PEA and MAP on the MSR. (A) : PEA-HCl $1 \mathrm{mg} / \mathrm{kg}$, i.v.; $\bigcirc$ : reserpine + PEA-HCl $1 \mathrm{mg} / \mathrm{kg}$, i.v. (B) O: MAP-HCl $0.3 \mathrm{mg} / \mathrm{kg}$, i.v.; O: reserpine $+\mathrm{MAP}-\mathrm{HCl} 0.3 \mathrm{mg} / \mathrm{kg}$, i.v. (C) : PEA-HCl $1 \mathrm{mg} / \mathrm{kg}$, i.v.; $\bigcirc:$ 6-hydroxydopamine + $\mathrm{PEA}-\mathrm{HCl} 1 \mathrm{mg} / \mathrm{kg}$, i.v. (D) O: $\mathrm{MAP}-\mathrm{HCl} 0.3$ $\mathrm{mg} / \mathrm{kg}$, i.v.; $\bigcirc$ 6-hydroxydopamine + MAP-HCl $0.3 \mathrm{mg} / \mathrm{kg}$, i.v. Reserpinc $(5 \mathrm{mg} / \mathrm{kg}, 24 \mathrm{hr}$ before, i.p.) and 6-hydroxydopamine $(200 \mu \mathrm{g}, 14$ days before, intracisternally) were preadministered. Inset figures in $\mathrm{C}$ and $D$ show the effects of drugs on blood pressure. Each point represents the change in the mean blood pressure $(\Delta \mathrm{mmHg}) .{ }^{*} \mathrm{P}<0.05$ ( $t$-test $)$, as compared with the effect of PEA or MAP alone. $\mathrm{n}=4$.

nized the enhancing effects of PEA and MAP on the MSR but not their pressor effects (Fig. 3 ). These results suggest that the increase of the MSR produced by PEA or MAP is not due to a change in blood pressure.

It was also possible that the MSR enhancement caused by PEA was duc to metabolites produced by conversion with type-B MAO. However, an inhibitor of type-B MAO, (-)deprenyl, did not reduce, but rather increased and prolonged the effect of PEA (Fig. 4). These results suggest that PEA itself increased the MSR.

There are abundant noradrenergic and serotonergic descending neurons innervating the spinal ventral horn, although dopaminergic innervation is very scarce (7). In our previous study, the serotonergic agonists, 5-methoxy$\mathrm{N}, \mathrm{N}$-dimethyltryptamine and 8-hydroxy-di- propylaminotetralin, and also 5-hydroxytryptophan, decreased the amplitude of the MSR $(9-11)$. We have shown previously that noradrenergic systems mediate facilitation of the spinal motoneurons $(8,17)$ and that tonic noradrenergic facilitation of the spinal reflexes occurs $(18,19)$. In the present preparation, although tonic activitics from the brain to the spinal cord were lost because of spinalization at the $\mathrm{C} 1$ level, the terminals of noradrenergic fibers descending from the brainstem were still viable.

The increase in the amplitude of the MSR induced by PEA and MAP was antagonized by the $\alpha_{1}$-blocker prazosin, but not by the $D_{1}$ antagonist SK\&F 83566- $\mathrm{HBr}(20)$ and the $\mathrm{D}_{2}$ antagonist YM-09151-2 (21) (Figs. 1 and 2). These results suggest that PEA and MAP increase the MSR via direct or indirect norad- 

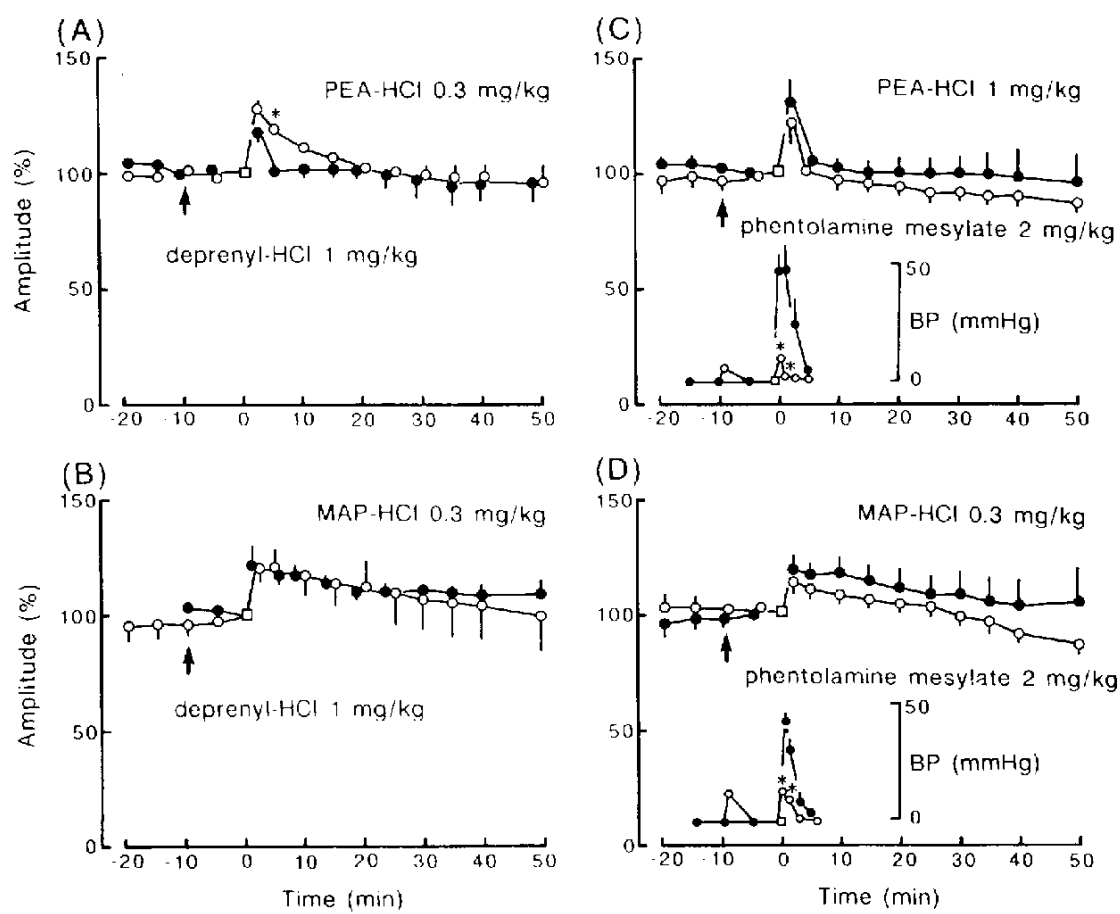

Fig. 4. Influence of $(-)$ deprenyl-HCl $(\mathrm{A}$ and $\mathrm{B})$ and phentolamine mesylate $(\mathrm{C}$ and $\mathrm{D})$ on the stimulatory effects of PEA and MAP on the MSR. (A) O: PEA-HCl $0.3 \mathrm{mg} / \mathrm{kg}$, i.v.; O: (-)deprenyl-HCl $1 \mathrm{mg} / \mathrm{kg}$, i.v. + PEA-HCl $0.3 \mathrm{mg} / \mathrm{kg}$, i.v. (B) : $\mathrm{MAP}-\mathrm{HCl} 0.3 \mathrm{mg} / \mathrm{kg}$, i.v.; O: (-)deprenyl-HCl $1 \mathrm{mg} / \mathrm{kg}$, i.v. + MAP-HCl $0.3 \mathrm{mg} / \mathrm{kg}$, i.v. (C) O: PEA-HCl $1 \mathrm{mg} / \mathrm{kg}$, i.v.; O: phentolamine mesylate $2 \mathrm{mg} / \mathrm{kg}$, i.v. + PEA-HCl $1 \mathrm{mg} / \mathrm{kg}$, i.v. (D) : MAP-HCl $0.3 \mathrm{mg} / \mathrm{kg}$, i.v.; $O$ : phentolamine mesylate $2 \mathrm{mg} / \mathrm{kg}$, i.v. + MAP-HCl $0.3 \mathrm{mg} / \mathrm{kg}$, i.v. Deprenyl and phentolamine were administered at the arrow. Inset figures in C and D show the effects of drugs on blood pressure. Each point represents the change in the mean blood pressure $(\Delta \mathrm{mmHg}) .{ }^{*} \mathrm{P}<0.05$ ( $t$-test), as compared with the effect of PEA or MAP alone. $\mathbf{n}=4$.

renergic mechanisms and exclude the possibility that PEA and MAP increase the amplitude of the MSR by releasing dopamine or by direct stimulation of dopamine receptors. Although dopaminergic agents have been reported to affect the MSR $(22,23)$, the involvement of dopamine release in the effects of PEA and MAP was not suggested in the present study. This may be due to the existence of little dopaminergic innervation in the ventral horn (7). Reserpine, which depletes monoamines in the monoaminergic terminals, and 6-hydroxydopamine, which destroys noradrenergic terminals more rapidly than dopaminergic terminals (16), antagonized the enhancing effects of PEA and MAP on the MSR. These findings suggest that PEA and MAP increase the amplitude of the MSR by rcleasing noradrenaline from the terminals of descending noradrenergic fibers.

In rats pretreated with prazosin or reserpine, PEA decreased the amplitude of the MSR. This may be due to the serotonergic agonistic action of PEA, which usually appears at high doses (14). The decrease of the MSR caused by PEA has been shown to be antagonized and reversed to enhancement by the serotonergic antagonist ketanserin (14). However, 6-hydroxydopamine treatment did not reverse the effect of PEA. This result was not consistent with the previous study (13) which showed the reversal after 6-hydroxydopamine treatment. The inconsistency may be due to a balance between the direct noradrenergic agonistic effect which is amplified after 6-hydroxydopamine treatment and the 
serotonergic agonistic action of PEA. In the present study, a low dose of PEA had noradrenergic stimulatory effects on the MSR similar to those of MAP, and a high dose of PEA produced a serotonergic depressant action on the MSR (14). Serotonergic effects of PEA have also been reported in behavioral experiments $(24,25)$.

From the present results, it is concluded that PEA and MAP increase the amplitude of the MSR by releasing noradrenaline from the terminals of descending noradrenergic nerve fibers and through $\alpha_{1}$-receptors, and that the mechanism of the enhancing effect of PEA on the MSR is similar to that of MAP.

\section{Acknowledgments}

This work was supported in part by a Grant-in-Aid for Scientific Research from the Ministry of Education, Science and Culture, Japan. We are grateful to Smith Kline \& French Labs., Pfizer and Yamanouchi for supplying SK\&F 83566-HBr, prazosin- $\mathrm{HCl}$ and YM-091512 , respectively.

\section{REFERENCES}

1 Inwang, E.E., Mosnaim, A.D. and Sabellig, H.C.: Isolation and characterization of phenylethylamine and phenylethanolamine from human brain. $\mathrm{J}$. Neurochem. 20, $1469-1473$ (1973)

2 Philips, S.R., Rozdilsky, B, and Boulton, A.A.: Evidence for the presence of $m$-tyramine, p-tyramine, and phenylethylamine in the rat brain and several areas of the human brain. Biol. Psychiatry 13, 51 - 57 (1978)

3 Borison, R.L., Havdala, H.S, and Diamond, B.I.: Chronic phenylethylamine stereotypy in rats: $A$ new animal model for schizophrenia? Life Sci. 21, $117-122$ (1977)

4 Cooper, S.J. and Dourish, C.T.: Hypodipsia, stereotypy and hyperactivity induced by $\beta$-phenylethylamine in the water-deprived rat. Pharmacol. Biochem. Behav. 20, I-7 (1984)

5 Dourish, C.T. and Cooper, S.J.: Environmental experience produces qualitative changes in the stimulant effects of $\beta$-phenylethylamine in rats. Psychopharmacology (Berlin) 84, 132-135 (1984)

6 Karoum, F., Chuang, L. $-W$. and Wyatt, R.J.: Presence and distribution of phenylethylamine in the rat spinal cord. Brain Res. 225, 442-445 (1981)

7 Björklund, A. and Skagerberg, G.: Descending monoaminergic projections to the spinal cord. In Brain Stem Control of Spinal Mechanisms, Edited by Sjölund, B. and Björklund, A., p. 55-88, Elsevier Biomedical Press, Amsterdam (1982)

8 Tanabe, M., Ono, H. and Fukuda, H.: Spinal $\alpha_{1^{-}}$ and $\alpha_{2}$-adrenoceptors mediate facilitation and inhibition of spinal motor transmission, respectively. Japan. J. Pharmacol. 54, 77-85 (1990)

9 Nagano, N., Ono, H., Ozawa, M. and Fukuda, H.: Sensitivity of spinal reflexes to TRH and 5-HT in 5,6-dihydroxytryptamine-treated rats. Eur. J. Pharmacol. 139, 315-321 (1987)

10 Nagano, N., Ono, H., Ozawa, M. and Fukuda, H.: The spinal reflex of chronic spinal rats is supersensitive to 5-HTP but not to TRH or 5-HT agonists. Eur. J. Pharmacol. 149, $337-344$ (1988)

11 Nagano, N., Ono, H. and Fukuda, H.: Functional significance of subtypes of 5-HT receptors in the rat spinal reflex pathway. Gen. Pharmacol. 19, $789-793$ (1988)

12 Hasebe, Y., Ono, H., Fukuda, H., Ohta, S. and Hirobe, M.: The most desirable conformation of phenylethylamine (PEA) moiety stimulating noradrenergic ncurons: Effects of PEA, methamphetamine, phenelzine, methylphenidate, nomifensine and mazindol on rat spinal reflexes. Gen. Pharmacol. 20, 375-379 (1989)

13 Hasebe, Y., Ono, H., Fukuda, H., Ohta, S. and Hirobe, M.: Enhancement of spinal monosynaptic reflexes with phenylethylamine and related drugs through descending noradrenergic neurons. I. Pharmacobiodyn. 12, 241-245 (1989)

14 Ono, H., Hascbe, Y., Mori, T., Fukuda, H., Kohno, M., Ohta, S. and Hirobe, M.: Structureactivity relationships of phenylethylamine analogs in their serotonergic depressant effects on the spinal monosynaptic reflex in rats. J. Pharmacobiodyn. 12, 384-391 (1989)

15 Welch, B.L.: A significance of the difference between two means when the population variances are uncqual. Biometrika 29, 350-362 (1937)

16 Jacks, B.R., De Champlain, J. and Cordeau, P.: Effects of 6-hydroxydopamine on putative transmitter substances in the central nervous system. Eur. J. Pharmacol. 18, 353-360 (1972)

17 Hirayama, T., Ono, H. and Fukuda, H.: Effects of adrenergic agents on ventral horn cells in rat spinal cord slices. Biomed. Res. 9, 343-351 (1988)

18 Hino, M., Ono, H. and Fukuda, H.: Brain stem involvement in the effects of chlorpromazine on the monosynaptic reflex of the rat lumbar spinal cord. Gen. Pharmacol. 17, 379-383 (1986)

19 Hino, M., Ono, H. and Fukuda, H.: Involvement of noradrenergic systems in the effects of con- 
ditioning stimulation of the lower brain stem on the lumbar spinal reflex in rats. Gen. Pharmacol. 18, 41 - 45 (1987)

20 O'Boyle, K.M. and Waddington, J.L.: SKF 83566 and 83692: Benzazepines with selective and stereospecific actions at the $D_{1}$ dopamine receptor. Br. J. Pharmacol. 83, Supp. 371P (1984)

21 Terai, M., Usuda, S., Kuroiwa, I, Noshiro, $O$. and Maeno, H.: Selective binding of YM-09152-2, a new potent neuroleptic, to $\mathrm{D}_{2}$-dopaminergic receptors. Japan. J. Pharmacol. 33, $749-755$ (1983)

22 Schlosser, W., Horst, W.D., Spiegel, H.E. and Sigg, E.B.: Apomorphine and its effects on the spinal cord. Neuropharmacology 11, 417-426
(1972)

23 Carp, J.S. and Anderson, R.J.: Dopamine receptor-mediated depression of spinal monosynaptic transmission. Brain Res. 242, 247-254 (1982)

24 Sloviter, R.S., Connor, J.D. and Drust, E.G.: Serotonergic properties of $\beta$-phenylethylamine in rats. Neuropharmacology 19, $1071-1074$ (1980)

25 Dourish, C.T.: Behavioural effects of acute and chronic $\beta$-phenylethylamine administration in the rat: Evidence for the involvement of 5-hydroxytryptamine. Neuropharmacology 20, 1067-1072 (1981) 